\title{
Short Communication: Apoptosis Regulates Passive Immune Transfer in Newborn Kids
}

\author{
A. Castro-Alonso, ${ }^{*}$ N. Castro, $†$ J. Capote,‡ A. Morales-delaNuez, $†$ I. Moreno-Indias, $†$ D. Sánchez-Macias, $\dagger$ \\ P. Herraez, ${ }^{*}$ and A. Argüellot ${ }^{1}$ \\ *Department of Morphology, and \\ †Department of Animal Science, Las Palmas de Gran Canaria University, Arucas 35413, Spain \\ ¥Canary Agronomic Science Institute, La Laguna, Tenerife 38200, Spain
}

\begin{abstract}
Ten newborn kids were used to evaluate the relationship between apoptosis and passive immune transfer in neonatal enterocytes. Kids were slaughtered in groups of 2 at birth, 1, 2, 3, or $60 \mathrm{~d}$ postpartum, and samples of duodenal epithelium collected from each animal. Samples were fixed, dehydrated, and embedded in paraffin wax. Sections were assessed for apoptotic cells and immunostained for IgG. Our results suggest that IgG absorption is mediated by apoptotic enterocytes. Thus, delaying apoptosis may improve the success of passive immune transfer.
\end{abstract}

Key words: apoptosis, enterocyte, immune passive transfer, immunoglobulin $\mathrm{G}$

The placenta in ruminants impedes Ig transfer to the fetus; consequently, goat kids must consume colostrum to acquire immunity early after birth (Castro et al., 2005). Few studies have focused on the relationship between enterocytes in newborn ruminants and IgG absorption. Micropinocytotic IgG transfer has been demonstrated in newborn calf enterocytes, but it is unclear whether a receptor-mediated transport system also exists (Jochims et al., 1994). There has been some speculation about the possible relationship between Fc receptors in enterocytes and immune passive transfer in newborn lambs (Mayer et al., 2002). However, the Fc receptors stimulate the phagocytic activity of the intestinal epithelial cells. An affinity-purified Fc-Rnspecific antiserum did not stain the cytoplasm of enterocytes in newborn lambs, even though a positive reaction was detected in the apical portion of crypt epithelial cells (Mayer et al., 2002).

Although enterocyte and intestinal epithelial cell apoptosis in newborn animals has been studied to a limited degree (Biernat et al., 2003; David et al., 2003),

Received October 30, 2007.

Accepted February 6, 2008.

${ }^{1}$ Corresponding author: aarguello@dpat.ulpgc.es the relationship between apoptosis and IgG absorption is unknown. The aim of this work was to determine the relationship between enterocyte apoptosis and immune passive transfer in newborn goat kids.

Experimental animal procedures were approved by the Ethical Committee of Las Palmas de Gran Canaria University. A pool of fresh goat colostrum $(41.2 \mathrm{mg}$ of $\mathrm{IgG} / \mathrm{mL}$ of colostrum, $9.5 \%$ protein, $7.3 \%$ fat) was refrigerated $\left(4^{\circ} \mathrm{C}\right)$ until use (no more than $\left.48 \mathrm{~h}\right)$. A total of 10 male newborn kids $(3.5 \pm 0.2 \mathrm{~kg}$ of $\mathrm{BW})$ born during a 2-d interval from 10 Majorera dams, a Canary Island (Spain) autochthonous dairy goat breed, were used. Kids were randomly assigned to 5 treatment groups and slaughtered in pairs at different age intervals (at birth, and 1, 2, 3, or $60 \mathrm{~d}$ of age). As described by Castro et al. (2005), kids were bottle fed with the colostrum pool twice on the day of birth $(2$ and $14 \mathrm{~h}$ postpartum). Each feeding provided 2,000 mg of IgG/ $\mathrm{kg}$ of BW (i.e., the total IgG received by each kid was $4,000 \mathrm{mg} / \mathrm{kg}$ ). From 2 to $60 \mathrm{~d}$, kids were fed by a milk replacer machine (Mini Robot, Divasa Farmavic, Vic, Spain) as described by Argüello et al. (2004).

After kids were slaughtered, duodenum samples were fixed in $10 \%$ neutral-buffered formalin, dehydrated through graded alcohol solutions and embedded in paraffin wax. Sections (3 $\mu \mathrm{m}$ thick) were dewaxed, rehydrated, and incubated with $0.3 \%$ hydrogen peroxide in methanol for 30 min at room temperature to block endogenous peroxidase activity. Tissue sections were then treated with pronase (Sigma Chemical Co., St Louis, $\mathrm{MO}$ ) and diluted in PBS, $\mathrm{pH} \mathrm{7.2,} \mathrm{for} 5 \mathrm{~min}$ at room temperature. A commercial terminal deoxynucleotidyl transferase, dUTP, nick-end labeling (TUNEL) assay kit (ApopTag, Chemicon International Inc., Billerica, MA) was used according to the manufacturer's instructions to visualize apoptotic cells. Sections were covered with an equilibration buffer for $20 \mathrm{~min}$ at room temperature, and terminal deoxynucleotidyl transferase (TdT) was applied and sections were incubated in a humidified chamber at $37^{\circ} \mathrm{C}$ for $1 \mathrm{~h}$. Slides were washed with stop/wash buffer for $10 \mathrm{~min}$ at room temperature and 


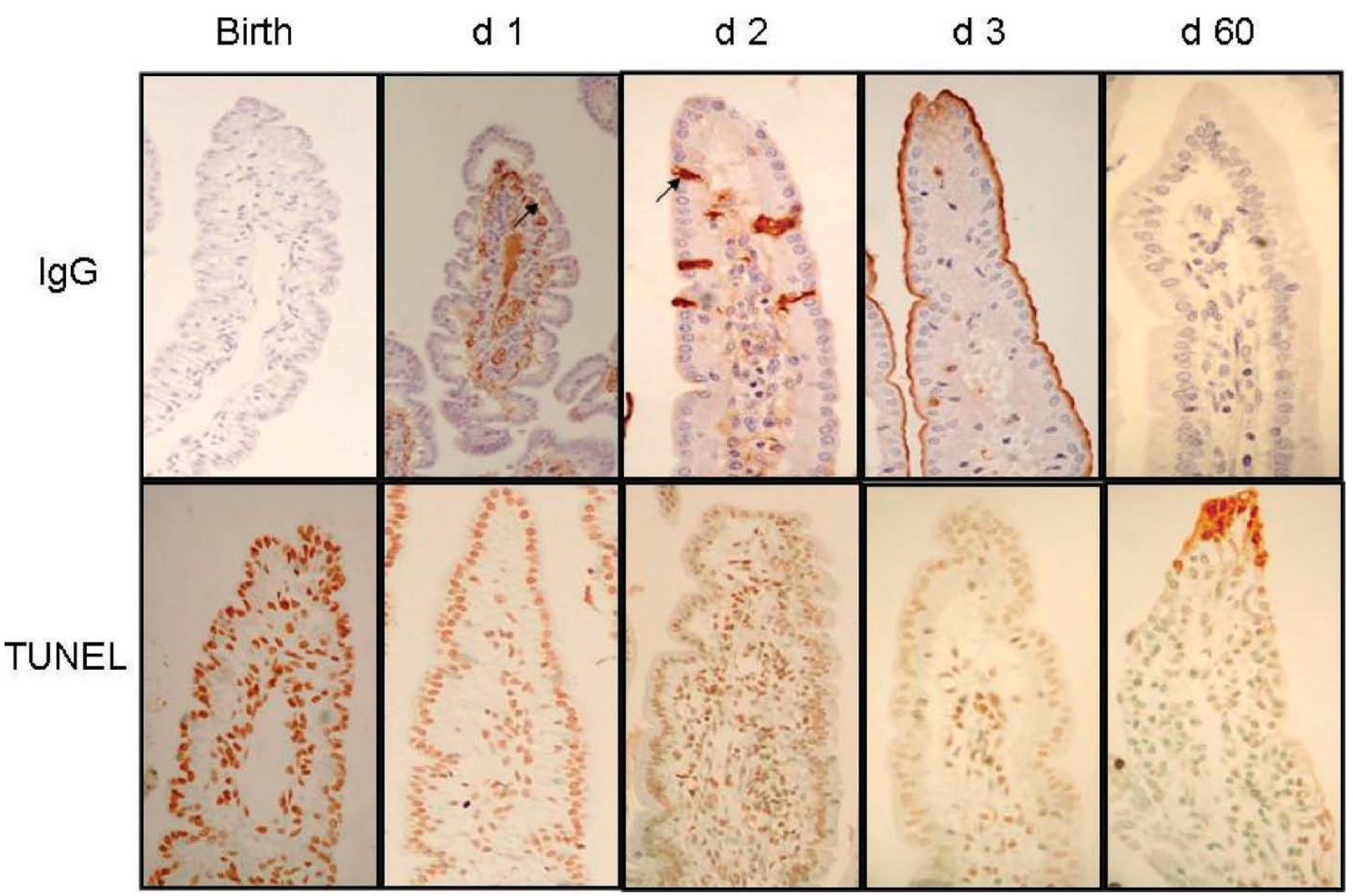

Figure 1. Terminal deoxynucleotidyl transferase, dUTP, nick-end labeling (TUNEL) and IgG staining in duodenum of goat kids slaughtered at birth or at $1,2,3$, or $60 \mathrm{~d}$ of age.

incubated with anti-digoxigenin conjugate for $30 \mathrm{~min}$ at room temperature in a humidified chamber. The chromogen 3-3'diaminobenzidine tetrahydrochloride was used to develop the reaction. Sections were washed in distilled water, counterstained with methyl green for $10 \mathrm{~min}$ at room temperature, dehydrated, and mounted.

Table 1. Immunoglobulin G and apoptosis reactive cell counts in duodenal samples from newborn kids

\begin{tabular}{llcccccc}
\hline & & \multicolumn{6}{c}{ Day of life } \\
\cline { 3 - 7 } Cells reactive to & Tissue & 0 & 1 & 2 & 3 & 60 & SEM \\
\hline \multirow{2}{*}{ IgG } & Crypts & $0^{\mathrm{a}}$ & $1.6^{\mathrm{b}}$ & $0^{\mathrm{a}}$ & $0^{\mathrm{a}}$ & $0^{\mathrm{a}}$ & 0.1 \\
& Middle & $0^{\mathrm{a}}$ & $5.0^{\mathrm{b}}$ & $2.6^{\mathrm{b}}$ & $0^{\mathrm{a}}$ & $0^{\mathrm{a}}$ & 0.4 \\
TUNEL $^{1}$ & Apex & $0^{\mathrm{a}}$ & $20.1^{\mathrm{b}}$ & $4.1^{\mathrm{a}}$ & $3.3^{\mathrm{a}}$ & $0^{\mathrm{a}}$ & 1.4 \\
& Crypts & $34.4^{\mathrm{a}}$ & $4.6^{\mathrm{b}}$ & $0.5^{\mathrm{c}}$ & $0^{\mathrm{c}}$ & $1.6^{\mathrm{c}}$ & 2.1 \\
& Middle & $63.0^{\mathrm{a}}$ & $0.4^{\mathrm{b}}$ & $0^{\mathrm{b}}$ & $0^{\mathrm{b}}$ & $0.4^{\mathrm{b}}$ & 4.1 \\
& Apex & $45.2^{\mathrm{a}}$ & $18.2^{\mathrm{b}}$ & $7.9^{\mathrm{b}}$ & $6.0^{\mathrm{b}}$ & $13.4^{\mathrm{b}}$ & 2.7 \\
\hline
\end{tabular}

${ }^{\mathrm{a}-\mathrm{c}}$ Values in the same row with different superscripts differ at $P \leq$ 0.05 .

${ }^{1}$ TUNEL $=$ terminal deoxynucleotidyl transferase, dUTP, nick-end labeling.
Negative control sections, processed simultaneously, were treated with PBS lacking TdT.

For IgG immunohistochemistry, sections were covered with $10 \%$ normal rabbit serum in PBS for 30 min at room temperature. A rabbit polyclonal primary antiIgG antibody (diluted 1:2,000 in PBS; A0193, Dako, Glostrup, Denmark) was applied for $18 \mathrm{~h}$ at $4^{\circ} \mathrm{C}$. A biotinylated swine anti-rabbit IgG (E0353, Dako) diluted 1:200 in PBS containing 1\% rabbit serum was then applied for $30 \mathrm{~min}$ at room temperature. The avidin-biotin peroxidase complex method (Vector Laboratories, Burlingame, CA) was applied as the third reagent, and 3-3'diaminobenzidine tetrahydrochloride was used to develop the immunoreaction. Sections were lightly counterstained with Harris's hematoxylin for 1 min, washed in tap water, dehydrated, and mounted. Negative control sections, processed simultaneously, were treated with PBS lacking the primary antibody. Positively labeled apoptotic and IgG cells were counted in 10 sections per animal from crypts, middle, and apex of the intestinal villus using a light microscope (Olym- 
pus BX41, Olympus Corporation, Tokyo, Japan) at $1,000 \times$ magnification. A GLM procedure was performed to evaluate the effect of sample time on apoptosis and IgG reactive cells count; SAS software (v9.0, SAS Institute Inc., Cary, NC) was used for statistic analysis.

Staining by TUNEL, which identifies apoptotic cells, and IgG immunohistochemistry of the duodenum in neonatal goat kids are shown in Figure 1. There was no IgG immunoreactivity in the duodenum at birth because animals had not yet been fed colostrum; indeed, Table 1 shows no IgG-reactive cells at birth. Positive TUNEL staining, however, was apparent in almost all villi cells (Figure 1, TUNEL at 0 d; Table 1). Enterocyte apoptosis has also been reported in neonatal pigs (Biernat et al., 2003) but has not been studied in neonatal ruminants. Apoptosis can be seen in the center of the villi at $d 0$, because the villi are reconstructing all the structure.

On d 1 of age, IgG was internalized and transported by enterocytes (Figure 1; arrow in IgG for d 1), and accumulated in the vascular villi system (Jochims et al., 1994). Positive TUNEL staining for apoptosis was significantly reduced at this age (Table 1). Thus, IgG absorption was related to apoptotic changes in enterocytes. Serum blood IgG was not recorded in the present experiment, but previous experiments (Castro et al., $2005,2007)$ demonstrated that the main period for IgG absorption in kid goats was the first $24 \mathrm{~h}$ of life. On d 2 of life, the cytoplasm and vascular villi of some enterocytes displayed marked IgG immunostaining (Figure 1; arrow in IgG on d 2). In contrast, TUNEL staining was markedly reduced after $\mathrm{d} 2$ of life (Table 1). Thus, IgG was found bound to enterocytes but was not internalized (Figure 1; IgG on d 3). Positive TUNEL staining for apoptosis was modest at this time point (Figure 1; TUNEL on d 3, Table 1). Immunoglobulin G immunostaining was not observed in kids slaughtered at $60 \mathrm{~d}$ of age, and apoptosis was limited to a few cells at the apex (Table 1) of the intestinal villi (Figure 1; TUNEL on $d 60$ ).
In conclusion, we have elucidated a new gating mechanism for passive immune transfer in ruminants, although further experiments are necessary to discover if the mechanism of IgG absorption is connecting with apoptotic events. Absorption of $\mathrm{IgG}$ is a time-dependent process that lasts for $48 \mathrm{~h}$. Apoptosis in the small intestine is influenced by the composition of colonizing commensal bacteria in neonatal gnotobiotic pigs (Willing and Van Kessel, 2007). Thus, further research is required to determine how to delay apoptosis successfully in newborn ruminants and consequently increase the success of passive immune transfer in these animals.

\section{REFERENCES}

Argüello, A., N. Castro, and J. Capote. 2004. Growth of milk replacer kids fed under three different managements. J. Appl. Anim. Res. 25:37-40.

Biernat, M., J. Wolinski, M. M. Godlewski, T. Motyl, J. Morisset, and R. Zabielski. 2003. Apoptosis in the gut of neonatal piglets. Pages 46-48 in Proc. 9th Int. Symp. Digestive Physiology in Pigs, University of Alberta, Edmonton.

Castro, N., J. Capote, S. Alvarez, and A. Argüello. 2005. Effects of lyophilized colostrum and different colostrum feeding regimens on passive transfer of immunoglobulin $\mathrm{G}$ in Majorera goat kids. J. Dairy Sci. 88:3650-3654.

Castro, N., J. Capote, L. Morales, E. Quesada, H. Briggs, and A. Argüello. 2007. Short communication: Addition of milk replacer to colostrum whey, effect on IgG passive transfer in Majorera kids. J. Dairy Sci. 90:2347-2349.

David, C. W., J. Norman, H. M. Hammon, W. C. Davis, and J. W. Blum. 2003. Cell Proliferation, apoptosis, and B- and T- lymphocytes in Peyer's patches of the ileum, in thymus, and in lymph nodes of preterm calves, and in full-term calves at birth and on day 5 of live. J. Dairy Sci. 86:3321-3329.

Jochims, K., F. J. Kaup, and W. Drommer. 1994. An immunoelectron microscopic investigation of colostral IgG absorption across the intestine of newborn calves. Res. Vet. Sci. 57:75-80.

Mayer, B., A. Zolnai, L. Frenyo, V. Jancsik, Z. Szentirmay, L. Hammarstrom, and I. Kacskovics. 2002. Redistribution of the sheep neonatal Fc receptor in the mammary gland around the time of parturition in ewes and its localization in the small intestine of neonatal lambs. Immunology 107:288-296.

Willing, B. P., and A. G. Van Kessel. 2007. Enterocyte proliferation and apoptosis in the distal small intestine is influenced by the composition of colonizing commensal bacteria in the neonatal gnobiotic pig. J. Anim. Sci. 85:3256-3266. 